\title{
Community flood resilience assessment frameworks: a review
}

\author{
Dejene Tesema Bulti ${ }^{1}$ Birhanu Girma ${ }^{2} \cdot$ Tebarek Lika Megento $^{2}$
}

Received: 27 March 2019 / Accepted: 9 November 2019 / Published online: 25 November 2019

(c) Springer Nature Switzerland AG 2019

\begin{abstract}
In response to the inadequacy of flood control infrastructures under uncertainties, building community resilience has become a vital concern in modern flood risk management for flood mitigation and recovery options. Relatedly, there has been growing recognition of the importance of community flood resilience measurement, and several tools to measure resilience have been introduced since the turn of this century. However, overall yield from resilience works can be compromised if the measurements do not conform to theoretical basis. By identifying evaluation methodology which takes the multifaceted nature of resilience into account, this study analyzed existing community flood resilience measurement tools. The results show that the importance of assessing and enhancing community competence in flood resilience building is unnoticed by the majority of the analyzed frameworks. Adopting a participatory approach and measurement under uncertainties are overlooked by a significant proportion of the frameworks. Moreover, issues of spatial and temporal interdependencies have received less attention. Consequently, the multi faceted nature of resilience appears inadequately addressed in existing frameworks, and measurements of community flood resilience tend to be inconsistent. The study would support efforts being made to improve consistency and effectiveness community flood resilience measurements and to operationalize the concept of resilience in flood disaster management.
\end{abstract}

Keywords Urban flood · Measuring resilience $\cdot$ Community flood resilience $\cdot$ Flood risk management

\section{Abbreviation \\ CFRA Community flood resilience assessment}

\section{Introduction}

Nowadays, flood has become the most frequent natural hazard posing significant social, economic and environmental damages across the globe with high level of vulnerability of urban areas [1-5]. Over the years, the use of flood control infrastructures has been regarded as the predominant method for urban flood mitigation [6, 7]. However, conventional engineering approaches to design such infrastructures assume that the pattern of flow variability remains unchanged over time [8]. Therefore, flood control infrastructures are unlikely reliable under uncertainties arising from human-nature couplings such as climate change and urbanization [6, 9-11].

Since recent decades, attention is shifting toward resilience-based strategies for flood mitigation and recovery options $[12,13]$. Resilience is a contested concept that has been exposed to different definitions in various disciplines and contexts [14-16]. For instance, in engineering, resilience refers to a system's ability to resist and return to original state [6]. In ecology, it is associated with the change that the system can tolerate and the capacity to reorganize or renew, irrespective of the state [12,17]. Application of the resilience concept in urban planning and natural hazard management is recent, as compared to in engineering and in ecology $[6,18]$, yet it has been increasingly used to provide a means to manage risks due to unexpected shocks and to realize sustainability over time [19-24].

Dejene Tesema Bulti, dejenetesema@yahoo.com; dejene.tesema@eiabc.edu.et; Birhanu Girma, birhanu.girma@eiabc.edu.et; Tebarek Lika Megento, tebarek.lika@aau.edu.et | 'Department of Urban and Regional Planning, Ethiopian Institute of Architecture, Building Construction and City Development, Addis Ababa University, Addis Ababa, Ethiopia. ${ }^{2}$ Addis Ababa University, Addis Ababa, Ethiopia. 
In line with the grown concern of enhancing disaster resilience, the issue of methods and instruments for measuring resilience has captured a significant attention in disaster risk management. Supporting decision making processes, resilience measurement tools enable to assess the level to which a particular system is resilient to various shocks, to understand where intervention is needed and to choose options for actions [25-28]. These tools allow to establish baselines and to monitor progress in improvements of resilience over time [28-31]. Besides, resilience measurement frameworks can be used to evaluate effectiveness of resilience building interventions. Moreover, the results obtained from the resilience measurements of different scales can be used to undertake a comparison with best practice standards or between individuals, groups, communities, regions and countries [32]. Such comparison can provide a platform for experience sharing between peers. Exposure to different experiences can generate initiations to try new practices toward enhancement of their resilience. Finally, an assessment tool developed and implemented through participatory approach improves local understanding of risk and resilience, which in turn increases the coordination between all stakeholders in the planning and implementation of resilience building actions [32].

Despite increased understanding and application of the resilience concept across disciplines, there is still an absence of consensus concerning consistency in its measurement $[25,32]$. Regarding to the question "resilience to what?", some of the measurement frameworks are designed to operate in multiple shocks, whereas others aim to function in the context of particular hazards. Multi-hazard frameworks mostly use general resilience indicators. On the other hand, hazard-specific frameworks include specific indicators enabling to capture greater detail of information related to a particular hazard.

Based on an approach (top-down or bottom-up) adopted in their development process, the resilience assessment frameworks can differ in the selection of indicators. For instance, most of the frameworks mainly used for standardization of data and undertaking comparison across scales are developed using top-down approach [33]. They use general indicators and more suitable under data variability and contextual differences. In contrast, some frameworks are developed based on participatory (bottom-up) approach using substantial input from potential stakeholders, and they include more details and specific indicators [34].

On the other hand, the temporal phases of disaster in which resilience is measured affect the choice of variables in index construction. Particularly, in assessing the results of resilience building programs, some frameworks are more suitable to conduct a broad measurement of resilience capacities using more indicators to better reflect the details required for program intervention, and they usually applied before a disaster. However, frameworks aiming at measuring response and recovery after a disaster use a limited set of indicators [32].

Variation in the scales at which different disciplines consider resilience is also an important factor influencing the selection of indicators. For example, urban planning-oriented frameworks mostly focus on higher-level indicators such as municipal planning process and communication system in contrast to household level indicators, which are common for frameworks dealing with disaster risk reduction [35]. Moreover, resilience is multi-dimensional such as physical, social, financial, institutional, etc., and it is difficult to decide which component exactly leads a particular community to resilient $[2,36]$. Hence, different sectors conceptualize resilience components differently; therefore, differences appear in the design of frameworks. Given these constraints, a number of tools have been developed and implemented at various spatial scales (local to global) with or without participatory approach in different contexts: pre-disaster to post-disaster, shock-specific to multiple hazards.

Several researchers studied the contents of resilience measurement tools, the general formats in which the frameworks are structured and the methods for the development of the tools. Monaghan et al. [39] studied key features of six community resilience assessment toolkits. Winderl [32] mapped and discussed the characteristics of twenty-seven national and community-level resilience assessment tools. Lavelle et al. [33] provided a critical review of nine disaster resilience measurement methodologies based on five major criteria. Hughes and Sharman [11] compared and contrasted the main features of five resilience assessment frameworks selected from diverse alternative approaches to complex issues of resilience. Examining seventeen resilience assessment frameworks, Schipper and Langston [29] reported the disparities between resilience theory and the focuses of indicators used in resilience assessment frameworks. In line with relatively new, but growing concept of resilience measurement in research and practice, it has been emphasized that more studies are required in order to enhance understanding and operationalization of the concept of resilience measurement in different disciplines [24, 29, 32].

Although the above-acknowledged studies have provided insight into the characteristics of resilience measurement tools, attempts to review resilience measures focusing on specific hazard are limited. The diverse understanding of the resilience concept in different disciplines makes the intent of the resilience assessment frameworks mostly remain within the body of knowledge deduced from their own field of studies 
[30]. Therefore, they could give slightly diverse directions on the indicators that contribute to the resilience of a particular hazard. With this regard, analyzing resilience assessment tools using hazard-oriented approach enables to pinpoint required improvements specific to the hazard, thereby supporting the efforts being made to establish a consistent basis of measurements and to enhance operationalization of the resilience concept. In addition, it provides the main features of the resilience assessment tools which can support decisions how and when to select, arrange or integrate the frameworks under different settings, since each tool could be more suitable for one or more phases of a particular application (e.g., in stages of disaster risk management cycle). It can also highlight how resilience is being recognized and assessed in various fields of studies. Particularly, in line with the increasing interest of resilience-based flood risk management [19-22], improved understanding of how resilience measurement is being operationalized in the context of flood hazard, merits further analysis.

Hence, the central aim of this study is to analyze existing community flood resilience assessment (CFRA) tools by examining whether the multifaceted nature of resilience has been addressed in their development and implementation processes. More specifically, it is conducted (i) to provide an overview of existing CFRA frameworks; (ii) to define evaluation criteria for CFRA, taking into account the multifaceted nature of resilience; (iii) to evaluate the frameworks against the evaluation criteria.

\section{Materials and methods}

\subsection{Selection of frameworks}

The resilience measurement frameworks were accessed through a blind search in Google and Google scholar both in March and in September 2018. Keywords such as tool, model, index, measure, framework in combination with flood resilience were used in the search. As a result, twenty-eight resilience assessment frameworks were identified. The contents of the documents were examined to identify if they are reporting for frameworks developed for specific to flood resilience or to multiple natural disaster resilience with the inclusion of flood hazard. The study excluded frameworks designed to measure resilience of single component such as street networks [5] and railway transport [41]. This produced a total of seventeen resilience assessment frameworks shown in Table 1. Further, documents such as manuals, journal articles, reports and guidelines related to the selected tools were used in the review.

\subsection{Overview of the selected CFRA frameworks}

Overall, majority of selected frameworks (Table 1) have been released since last decade, highlighting the application of resilience measurement is recent. The frameworks are developed by researchers, governmental institutions and international donor organizations. Although they are slightly different in their focus and application, most of the frameworks appear primarily developed to assess resilience of developed countries. However, assessment frameworks developed by non-local professionals may have little potential to properly address the context specificity of flood resilience of local community of developing countries.

Further, the frameworks are structured into four general formats: index, scorecard, model and toolkit. Indices usually use the sum of scores acquired for all indicators of the measurement framework, and mostly they rely on quantitative data for producing an index value. The value can be a single value aggregated from all indicators used in the assessment tool, or more commonly, as sets of values related to respective resilience dimensions [42, 43]. This format is more transparent and easy to understand; at the same time, if the value is obtained based on some standardization, it can be used for comparison purpose (e.g., between communities). More than half of the selected frameworks have been structured in index format. In contrast, scorecard format has been used in few tools. It is a list of questions to help community members to assess their resilience in each dimension in the resilience measurement frameworks. Scorecard is simple to use and mostly utilized when the emphasis is to prepare a community to adapt future change $[44,45]$.

The use of modeling approach has also been introduced in fewer number of selected tools. Model simplifies the complex relationship between resilience assessment variables $[5,46]$. By using the past and current data on flood impact as input to mathematical algorithms for scenario analyses, it can be used to estimate future conditions, and it allows to assess the expected damages in a given year. This offers opportunity to set a goal of resilience building interventions. By measuring improvements in the resilience at a given year as a result of resilience building action, and comparing the result with a modeling output of the respective year, it is possible to better interpret the progress (implying the effectiveness of resilience building interventions) over a specific period of time [38]. The same number of proportion of tools has been developed in toolkit format. With a broader scope, the toolkit uses one or a combination of the above mentioned formats. It establishes assessment procedures, and outline mechanisms for identifying assessment criteria [45]. 
Table 1 Basic information of the community flood resilience assessment frameworks selected for analysis

\begin{tabular}{|c|c|c|c|c|c|c|}
\hline Framework/tool & Denotation & $\begin{array}{l}\text { Year of initial } \\
\text { development }\end{array}$ & Developers & Focus & General format & References \\
\hline $\begin{array}{l}\text { Coastal Community Resilience } \\
\text { Toolkit }\end{array}$ & CCR & 2007 & $\begin{array}{l}\text { U.S. Indian Ocean Tsunami } \\
\text { Warning System Program. }\end{array}$ & US & Toolkit & [47] \\
\hline $\begin{array}{l}\text { Community and Regional Resil- } \\
\text { ience Initiative }\end{array}$ & CARRI & 2008 & $\begin{array}{l}\text { Community and Regional Resil- } \\
\text { ience Initiative }\end{array}$ & US & Index & [37] \\
\hline $\begin{array}{l}\text { Community Disaster Resilience } \\
\text { Framework }\end{array}$ & CDRF & 2009 & Academia & US & Index & [48] \\
\hline $\begin{array}{l}\text { The PEOPLES Resilience Frame- } \\
\text { work }\end{array}$ & PEOPLES & 2010 & $\begin{array}{l}\text { National Institute of Standards } \\
\text { \& Technology }\end{array}$ & US & Index & [49-51] \\
\hline $\begin{array}{l}\text { Coastal Community Resilience } \\
\text { Index }\end{array}$ & CCRI & 2010 & Academia & US & Index & {$[52]$} \\
\hline $\begin{array}{l}\text { Baseline Disaster Resilience } \\
\text { Indicators }\end{array}$ & BDRI & 2010 & Academia & US & Index & [42] \\
\hline Flood Resilience Index & FRI & 2013 & Academia & Europe \& Asia & Index & {$[14,53]$} \\
\hline $\begin{array}{l}\text { Community Disaster Resilience } \\
\text { Scorecard }\end{array}$ & CDRS & 2013 & Academia & Australia & Scorecard & {$[45,54]$} \\
\hline $\begin{array}{l}\text { Resilient Communities Score- } \\
\text { card }\end{array}$ & RCS & 2013 & $\begin{array}{l}\text { Vermont Natural Resources } \\
\text { Council }\end{array}$ & US & Scorecard & [44] \\
\hline $\begin{array}{l}\text { Community Resilience Measure- } \\
\text { ment Framework }\end{array}$ & CRMF & 2013 & $\begin{array}{l}\text { United States Agency for Inter- } \\
\text { national Development }\end{array}$ & Global & Model & [38] \\
\hline $\begin{array}{l}\text { ARUP's City Resilience Frame- } \\
\text { work }\end{array}$ & CRF & 2014 & $\begin{array}{l}\text { The Rockefeller Foundation, } \\
\text { ARUP }\end{array}$ & Global & Index & [26] \\
\hline $\begin{array}{l}\text { IFRC Framework for Community } \\
\text { Resilience }\end{array}$ & FCR & 2014 & $\begin{array}{l}\text { The International Federation of } \\
\text { Red Cross and Red Crescent } \\
\text { Societies }\end{array}$ & Global & Toolkit & [55] \\
\hline $\begin{array}{l}\text { Australian Natural Disaster } \\
\text { Index }\end{array}$ & ADRI & 2016 & Academia & Australia & Index & [43] \\
\hline ResilSIM & ResilSIM & 2016 & Academia & US & Model & [46] \\
\hline $\begin{array}{l}\text { Community Flood Resilience } \\
\text { Measurement Tool }\end{array}$ & CRMT & 2017 & Academia & Global & Index & [28] \\
\hline $\begin{array}{l}\text { Community Disaster Resilience } \\
\text { Index }\end{array}$ & CDRI & 2017 & Academia & Latvia & Index & [55] \\
\hline $\begin{array}{l}\text { Maine Flood Resilience Check- } \\
\text { list }\end{array}$ & MFRC & 2017 & Maine Coastal Program & US & Scorecard & [57] \\
\hline
\end{tabular}

\subsection{Framework for evaluation}

\subsubsection{Definition of community flood resilience}

In order to develop criteria to analyze an approach used in the development and implementation of CFRA frameworks, it is essential to first elucidate what community flood resilience refers to. It combines two contested terms, "Community" and "Resilience," each of them are defined in different ways. In this study, community refers to a population of a flooded neighborhood with common geographic boundary or "shared fate." Further, drawing on an expanded definition of resilience proposed by Meerow et al. [16], the definition of community flood resilience is framed as:
Community flood resilience is the ability of a community -and all of its socio-ecological and socio-technical networks across temporal and spatial scales-to maintain or rapidly return to desired functions in the face of flood events, to adapt to change, and to transform systems that affect the current and future adaptive capacity.

It comprises of six basic features of resilience. First, it focuses on specific hazard (i.e., flood) which is concrete for evaluation. Second, a community is conceptualized as complex and adaptive system encompassing socio-ecological and socio-technical networks. Third, it acknowledges the importance of resilience in multiple spatial scales. Fourth, it recognizes the importance of resilience in 
different time period. Fifth, it recognizes that resilience is a combination of multiple capacities such as the capacity to recover after the flood, to adapt to a changing environment, and to transform. Finally, resilience is framed as an explicitly desirable state, suggesting negotiation among those who ratify it empirically.

\subsubsection{Analysis criteria}

In this study, criteria for analyzing the selected flood resilience assessment frameworks were developed through literature review. The criteria comprise not only those used to evaluate whether the basic features of the above definition (Sect. 2.3.1) have been addressed with the selected tools, but also include the criteria deemed necessary to improve the effectiveness of resilience measurements. With this respect, a community flood resilience assessment tool should inclusively address the array of community flood resilience, take into account the link between multiple spatial scales, be able to assess changes over time, be able to capture both the objective and subjective aspects of community flood resilience, develop suitable measures for capturing uncertainties, take into account the relative importance of indicators and be applied across different purposes. These criteria are further discussed in the remainder of this section.
2.3.2.1 Multi-dimensional measurement (inclusiveness) A community flood resilience draws on different interdependent dimensions. In this study, these dimensions were distilled from the indicators through the hierarchical structure with three levels. The first level comprises main categories of community flood resilience (dimensions). The second level is make-up of the components of the dimensions (sub-dimensions) and the third level was comprised indicators' sets that measure the status of components. In general, the community flood resilience dimensions are categorized into eight (Table 2), and each of these dimensions and related potential indicators are discussed below.

Environmental dimension indicates availability, accessibility and management of natural resources such as water and land that provide space to live and work. The availability of accessible natural resources has a significant role in enhancement of community resilience to flood [48, 56]. For instance, wetland can absorb impacts of flood and improve the recovery process. The quality and performance of natural assets can also be maintained through proactive resource management, such as absorption of fluvial flooding by upstream watershed $[26,47]$ and adequate conservation through erosion protection activities [55].

Physical dimension indicates the capability of the physical system, including built environment along with existing infrastructures to perform at acceptable levels

Table 2 Defined community flood resilience dimensions used to assess the multi-dimensionality of the selected frameworks

\begin{tabular}{|c|c|c|c|}
\hline Dimensions & Sub-dimensions & Dimensions & Sub-dimensions \\
\hline \multirow[t]{2}{*}{ Environmental } & Natural assets/resources & Community competence & Collective action and decision making \\
\hline & Conservation of natural resources & & $\begin{array}{l}\text { Critical reflection and problem solving } \\
\text { skills }\end{array}$ \\
\hline \multirow[t]{3}{*}{ Financial } & Structure & & Flexibility and creativity \\
\hline & Financial Security and stability & & Collective efficacy and empowerment \\
\hline & Dynamism & & Quality of life \\
\hline \multirow[t]{5}{*}{ Physical } & Facilities & Institutional (organizational) & Executive/administrative \\
\hline & Infrastructures & & Local institutions \\
\hline & Protective infrastructures & & Partnership \\
\hline & $\begin{array}{l}\text { Efficiency and maintenance of infrastruc- } \\
\text { tures }\end{array}$ & & Regulations/enforcements \\
\hline & Land use and structural design & & Education and training: \\
\hline \multirow{4}{*}{$\begin{array}{l}\text { Human (population } \\
\text { and demographic) }\end{array}$} & Composition & & Community participation and engagement \\
\hline & Socio-economic status & Technical & Early warning systems \\
\hline & Education attainment & & Emergency response \\
\hline & especial needs for assistance & & Recovery plans \\
\hline \multirow[t]{5}{*}{ Social/cultural capital } & Social networks & & Contingency plans \\
\hline & $\begin{array}{l}\text { Knowledge and skill in relation to past } \\
\text { events }\end{array}$ & & Resource management plan \\
\hline & Peace and security (safety) & & Hazard exposure and mapping \\
\hline & Social supports (norms, trust, etc.) & & \\
\hline & Social memory (place attachment) & & \\
\hline
\end{tabular}


during and after a flood event $[49,58,59]$. In addition, it includes all components those add redundancy and their interconnections (e.g., alternative routes, emergency response routes, evacuation pathways). In resilient community, infrastructures and facilities are efficient, robust and functional during and after flood events. Available and accessible infrastructure and community facilities (such as emergency shelters, healthcare) support emergency management [60]. Ensuring their functionality during flood events is essential for emergency response. Exposure can be reduced through the use of protective infrastructures. In addition, the level of community's resilience during and after flood event can be influenced by the robustness and efficiency of physical infrastructure as well as adequacy of maintenance [37]. Availability of effective land use plan and structural design that complements natural environment, economic and community aims together with planning regulation and building codes are also useful tools to reduce risks from floods $[47,50]$. In addition, land use plan prepared and implemented through participation of all stakeholders can facilitate coordination and helps to control and guide future development, which in turn, supports to reduce risks from flood $[26,58]$.

Financial dimension refers to the current economy (static) and ability to sustain economic growth (dynamic) [49] that influence the ability of the community to prepare for and recover from a flood event [43]. It includes diversity of income bases and access to financial resources [61]. Improved financial capital can enhance the capabilities of individuals to cope against disaster and speed up the recovery process $[37,62]$. In addition, increased potential for damage due to increased wealth can create a motivation for mitigation [43]. Economic security and stability has also an important role in building flood resilience. For instance, individual and collective asset bases (saving and convertible properties) can support a community coping strategies $[26,28]$. On the other hand, single-sector employment dependence of a community can increase the vulnerability during disruption [43]. Hence, access to different financial sources (credit schemes) support business development by allowing individuals to seek employment options during times of economic decline [26]. Moreover, availability of appropriate business mitigation plan reduces potential business interruptions and ensure financial security of the community [63]. On the other hand, a strong economic system enables the higher level to maintain infrastructure provision, and it helps to generate contingency funds required for emergencies and unexpected events. More of, attracting and retaining business through investments and economic diversity can help to overcome the economic declination due to disaster [51].

Human dimension indicates features of a community represented by the population and demographic factors that can influence capabilities of a community to withstand, prepare for and recover from adverse impacts from a flood event $[43,49]$. The factors can be categorized under different themes including composition, education attainment, physical ability of a community members and socioeconomic $[28,56,58]$. For instance, the financial resilience of a community depends on the capacity and skills of its working population to support the dependent population. In addition, negative impacts of flood hazards are usually unevenly distributed across the prone inhabitants or businesses within a particular community. In particular, flood events are expected to negatively impact more the elders and the poor. Hence, understanding who and why is vital for developing strategies for building resilience [57].

Social/cultural dimension indicates available social resources that a community can draw upon to maintain their livelihoods. It has been noted that sufficient social capital can improve solutions to collective action toward difficulties that arise due to flood and enhances cooperation and trust [64]. Its main characteristics include strong social networks, as well-established trust and participatory, inclusive processes, etc. $[59,64]$. Social network shows the level of community cohesion and tie that facilitate the social cooperation and coordination of mutual benefit [14, $49,56]$. Among others, by bridging between individuals and communities, it can facilitate the dissemination of proven good practices [38]. It enhances engagement and supports learning and adapting. On the other hand, place attachment has also important role because community that had experienced shocks differs from those which had not. Consequently, different communities could have different perspectives on, and priorities for, what makes them resilient. In addition, collective and individual knowledge capacity and experience of management of previous events, vulnerability and understanding of risk are an important input in building resilience of community $[38,56]$. Besides, community practice of coping with past events/crises or information on how it was done can be used in education and training. Moreover, collective principles of collaboration and high levels of trust increase the commitment of local stakeholders to genuine partnerships. Open debate within a leadership and community members establishes agreements about problems, solutions and priorities, etc.

Community competence reflects the reality that community resilience is both "bouncing back" and "bounce forward" through a rigorous and energetic effort which depends on the capability of a community to creatively envision a new future [49]. In essence, it captures the diverse community's abilities, including ability to develop multilayered solutions to complex problems, ability to participate in meaningful political networks and decision making and the community's perceptions to reflect 
positive change [34]. Moreover, it demonstrates the ability of the community to collectively believe that they able to rebuild, restructure and revive.

Institutional and organizational dimension refers to those responsible to execute flood disaster-related functions to realize resilience. It indicates the effectiveness of relationships among and within community organizations and entities. Effective planning and implementation requires committed, accountable and effective leadership characterized by comprehensive governance, including the government, corporate and civil society and evidence-based decision making [26]. Strong leadership can improve community resilience through strengthening the connection between various elements of the system such as bonding social networks [38]. Robust management practices create improved knowledge of system components and enables infrastructure managers to better prepare to restore interrupted services. Connectivity between various institutions enhances resilience [65]. Well-established (clear, agreed and stable) partnerships among local participant groups and institutions supports disaster risk reduction activities and emergency response $[38,60]$. In addition, it increases trust and knowledge exchange among members, consequently enhances participation toward planning for mitigation, preparation and recovery [66]. Legal frameworks for adaption and preparedness activities are essential to reduce the vulnerability of a community $[58,60]$. Provision of regular training and scenario exercises for a community with the inclusion of vulnerable groups enables the stakeholders to take appropriate action during risk reduction activities [26]. In addition, institutional learning better stored in the individual's memory. Collaborative training also facilitates innovation and creates opportunity for feedback and supports iterative management [18].

Technical dimension reflects the level of preparation for flood hazard events by examining how different activities are planned, communicated and implemented. Early warning system capable of reaching the whole community through formal information management and sharing system is regarded as an important contributor of disaster recovery and response system [60]. Timely access to relevant and manageable information increases community involvement and effectiveness of humanitarian assistance and local self-help operations [2]. Moreover, the availability of pre-prepared emergency plan enables to respond quickly in the event of flood [26]. It identifies and maintains emergency resources and infrastructure and communicating to the community. Contingency planning helps to ensure effective provision critical services (e.g., health services). Well prepared resource management plan improves effectiveness of monitoring, upgrading and renewal activities of existing resources. Moreover, disaster recovery plan prepared through community involvement prior to hazard event accelerates recovery, increase community participation in the recovery process and reduces adverse social, economic and environmental impacts.

2.3.2.2 Measurement at multiple spatial scales Resilience is a multi-scalar phenomenon (e.g., individual, household, community, city, region) which are often interlinked [14, 25]. What happens at a particular scale is reliant on the level of resilience at both lower and higher scales in the systems $[28,30,60,67]$. For instance, the resilience of a household can be influenced by resilience of a community, which in turn, can be influenced by resilience of a city. In this case, required improvements to build resilience of a particular scale can be associated with different scales of action and the relevant challenges associated with each. Understanding resilience at multiple levels helps planning the required interventions [35]. Hence, flood resilience assessment framework should enable to capture key sources of resilience at lower, focal and upper scales to improve understanding of hierarchical dependencies and interactions between the scales. In this study, taking the community as the central level of the analysis, individual and household levels are considered as a lower level whereas the higher level includes city and region.

2.3.2.3 Temporal aspects of measurement Resilience is dynamic and expected to change during the shift of the system to diverse states [37, 38]. Hence, building community resilience requires both ex-post and ex-ante strategies [25] as resilience of a particular time is inseparably linked to what precedes and succeeds. For instance, evaluating the community's ability to recover from past flood disasters helps to assess how it will react to future flood [56]. On the other hand, the level of community resilience before and after a flood events provides an information on the degree to which interventions (e.g., projects/programs to build resilience of a community) have been successful and the extent of recovery. Moreover, analysis along temporal band can help to assess the occurrence of a resilience transition [67]. Hence, the extent of attention paid to assess resilience in the context of a temporal band (past, present and future situations) can indicate the temporal aspects of the framework.

2.3.2.4 Addressing uncertainties The resilience of a community to future flood events is usually analyzed using an estimated risk of respective flood scenarios, which is the combined effect of inundation characteristics (extent, depth and speed), exposed elements and their susceptibility to the hydrological characteristics [68]. However, flood prediction models, although they benefit from continuous improvements, remain partly inaccurate due to uncertainties populated along data 
and data calculation processes [69]. Likewise, evaluation of exposure and susceptibility of elements at risk are associated with a certain level of uncertainties. Hence, our ability to predict future changes in social and environmental systems could not be absolute, and residual risks are always there. This inherent uncertainty can influence adaption thresholds to set long-term resilience goals. By making different scenarios and elaborating on alternate states, it is possible to improve understanding of the strengths and weaknesses that helps to be prepared for the most extreme conditions [38, 39]. Hence, planning for extreme scenarios is used as indicator to evaluate whether efforts have been made to address uncertainties.

2.3.2.5 Characterization and implementation The resilience assessment framework can be developed and implemented to measure objective or subjective aspect of resilience or the combination of both [40]. Objective measurement modes are mainly those approaches based on expert-elicitation or the academic literature. It relies on external judgment, including the process of direct measurement. On the other hand, subjective approach considers the individuals' understanding of their particular circumstances. It allows to consider the context specificity of resilience and enables to take community's own knowledge of their resilience into account [70]. Participation of prone community in the development and implementation has various benefits. For instance, during development process it ensures the selected criteria for assessment reflect the priorities of the target community and adds more context-specific elements [32, 38, 70]. On the other hand, during assessment process it provides a primary information [65]. However, using a combined approach can improve the accuracy of resilience assessment $[25,32,65]$ and local understanding of risk and resilience, which is important for planning in integrated flood risk management. In this regard, level of community participation in the development and implementation of the frameworks is used as an indicator of this criterion.

2.3.2.6 Relative contribution of indicators The contribution of each of the resilience assessment criteria can be influenced by contextual factors (e.g., the conceptualization of indicators may not be the same for different communities) and temporal factors [38, 48]. Hence, all resilience measurement indicators may have no equal importance in building community resilience. Indicators with more contribution to community resilience require emphasis in the computation of aggregated values. It can enhance effectiveness of planning. Hence, evaluating the extent to which the relative contribution of indicators has been considered in the frameworks is important.
2.3.2.7 Level of application Flood resilience assessment frameworks can be used for different purposes, including diagnostic, planning and evaluative [30, 32, 40, 55]. Diagnostic purpose indicates the mainly situational analysis to determine the extent to which a system (household, community, city, etc.) is resilient to flood. In the case of planning, it is used for articulating the intended outcomes of the resilience approach, and understanding the suitability of proposed project fits into the context of resilience building intervention. It also provides practical strategies on how to set in resilience goals into programs/projects addressing community flood resilience. On the other hand, evaluative purpose indicates the application of a given framework for assessing the extent to which resilience building initiatives/projects/programs have been successful in achieving their objectives (i.e., impact assessment), for instance, to evaluate enhancements in resilience capacities (as a result of specific interventions) with significant improvements in development outcomes. With this respect, applicability of a particular resilience assessment framework at all levels improves consistency of the result of resilience measurement. Hence, the functions for which the selected frameworks have been designed were assessed across the frameworks.

\section{Results}

The level of comprehensiveness and multi-dimensionality of the selected tools are assessed through studying their proposal on resilience dimensions. Each framework was examined with respect to defined community flood resilience dimensions. One challenge was that for some of the frameworks $[13,28,56]$ only sample indicators were provided. Hence, components of resilience dimensions (subdimensions) were used to assess usability of indicators. In this case, a particular component of resilience dimensions is considered, addressed, if at least one indicator is identified in the framework that can be categorized under the respective sub-dimensions. The number of complied components under each dimension was used in determination of level of comprehensiveness.

Table 3 shows flood resilience indicators used in each of the selected CFRA frameworks. Overall, the results illustrate that indicators related to all of the 36 components of community flood resilience dimensions have been utilized by multiple tools, albeit the total number of tools complied to each component is widely varied, ranging from 2 to 17.

In particular, it is clear that indicators associated with components such as economic structure, facilities, infrastructures, demographic composition, social networks, regulations/enforcements are reasonably well 


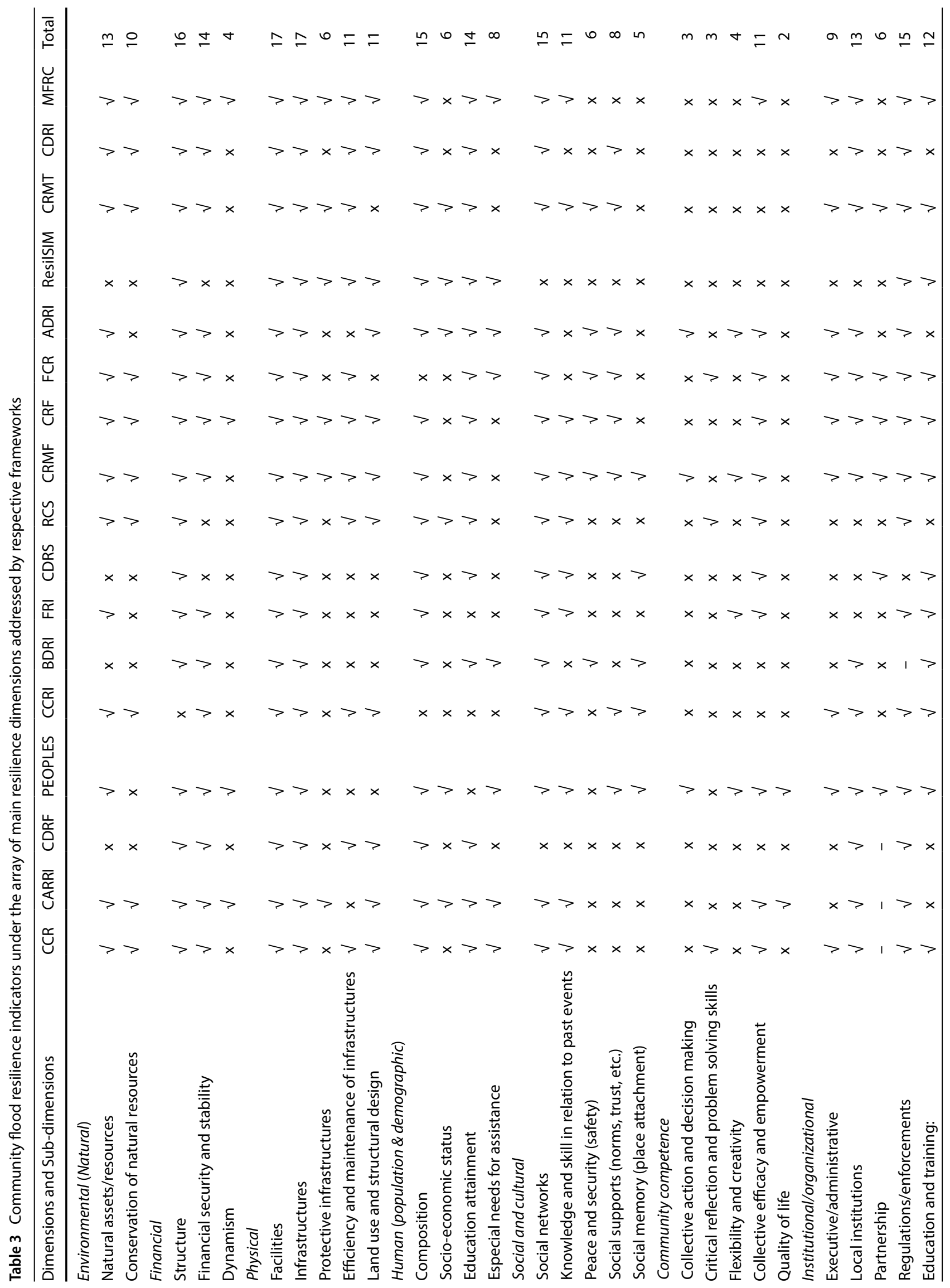




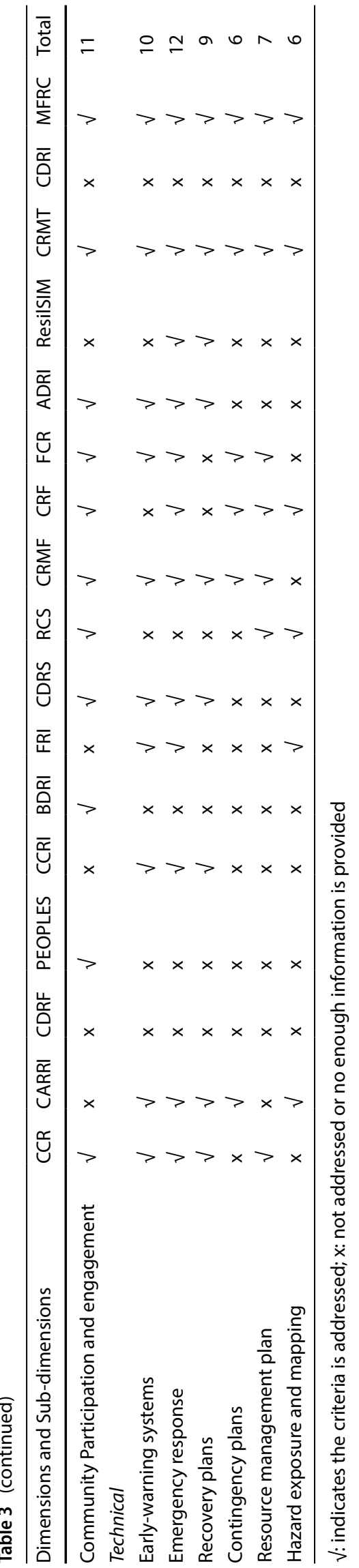

incorporated in majority of selected frameworks. Each of these components has received attention of at least 15 tools (nearly $90 \%$ of the analyzed tools). By contrast, it can also be seen that some of the components have received less attention. Specifically, indicators to assess the level of economic dynamism, social memory and place attachment, collective action and decision making, critical reflection and problem solving skills and flexibility and creativity of a community are largely overlooked by more than $25 \%$ of the analyzed tools.

Relatedly, Table 4 shows the percentage response of the selected CFRA tools against each of community flood resilience dimensions. The values are computed using the ratio of the number of components that have been used by each tool to the total number of sub-dimensions under respective dimensions. Rows and columns show the analyzed tools and community flood resilience dimensions, respectively. In addition, the proportion of the analyzed tools against the level of multi-dimensionality as well as each of the resilience dimensions is depicted in Fig. 1.

Overall, the selected tools have complied to more than one-half of the total community flood resilience dimensions indicating there has been recognition of multiple community flood resilience dimensions. In particular, nine tools (about $53 \%$ of the analyzed tools) have considered all of the eight resilience dimensions (Fig. 1a) regardless of the disparity in percentage response, while the least number of dimensions is identified in one tool (CDRF) which includes four dimensions: physical, financial, human and institutional. However, it is also evident that three tools (about $18 \%$ of the analyzed tools) have paid insignificant attention to at least one-third of the dimensions. These frameworks enable to conduct narrow measurements. This is commonly the case for frameworks designed by organizations or individuals with a particular interest in measuring a certain features of resilience. Further, detailed analysis reveals out of seventeen selected tools, only a pair of frameworks, CRMF and ADRI, have included all community flood resilience dimensions with the score of $50 \%$ and above, meaning they have addressed at least one-half of components of respective dimensions. This suggests that both tools could provide balanced detail of assessment across all dimensions as compared to the rests of the frameworks that have scored less than $50 \%$ in two or more dimensions.

Comparing between dimensions, it is clear from Fig. $1 \mathrm{~b}$ that three dimensions: physical, financial and institutional have been addressed in all of the analyzed frameworks. It can be seen that efforts have also made to address technical and environmental dimensions in equal proportion of the selected tools (76\%). On the other hand, community competence dimension has received less attention; specifically, it has been addressed in 11 tools $(65 \%$ of the 
Table 4 Level of comply by the analyzed CFRA frameworks to different flood resilience dimensions (\%)

\begin{tabular}{|c|c|c|c|c|c|c|c|c|c|}
\hline \multirow[t]{2}{*}{ Frameworks } & \multicolumn{9}{|c|}{ Main dimensions } \\
\hline & Environmental & Financial & Physical & Human & Social capital & $\begin{array}{l}\text { Community } \\
\text { competence }\end{array}$ & Institutional & Technical & Total response \\
\hline CCR & 100 & 67 & 80 & 75 & 40 & 40 & 83 & 67 & 8 \\
\hline CARRI & 100 & 100 & 80 & 100 & 40 & 40 & 33 & 83 & 8 \\
\hline CDRF & - & 67 & 80 & 50 & - & - & 33 & - & 4 \\
\hline PEOPLES & 50 & 100 & 40 & 75 & 80 & 80 & 100 & - & 7 \\
\hline CCRI & 100 & 33 & 80 & - & 80 & - & 67 & 50 & 6 \\
\hline BDRI & - & 67 & 40 & 75 & 60 & - & 50 & - & 5 \\
\hline FRI & 50 & 67 & 40 & 25 & 40 & 40 & 33 & 50 & 8 \\
\hline CDRS & - & 33 & 40 & 50 & 60 & 20 & 50 & 50 & 7 \\
\hline RCS & 100 & 33 & 80 & 75 & 40 & 40 & 33 & 33 & 8 \\
\hline CRMF & 100 & 67 & 100 & 50 & 100 & 60 & 100 & 83 & 8 \\
\hline CRF & 100 & 100 & 100 & 50 & 80 & 20 & 100 & 67 & 8 \\
\hline FCR & 100 & 67 & 60 & 50 & 60 & 40 & 100 & 67 & 8 \\
\hline ADRI & 50 & 67 & 60 & 100 & 60 & 60 & 67 & 50 & 8 \\
\hline ResilSIM & - & 33 & 100 & 100 & - & - & 33 & 33 & 5 \\
\hline CRMT & 100 & 67 & 80 & 75 & 80 & - & 100 & 100 & 7 \\
\hline CDRI & 100 & 67 & 80 & 50 & 40 & - & 33 & - & 6 \\
\hline MFRC & 100 & 100 & 100 & 75 & 40 & 20 & 83 & 100 & 8 \\
\hline Total & 13 & 17 & 17 & 16 & 15 & 11 & 17 & 13 & \\
\hline
\end{tabular}

(a)

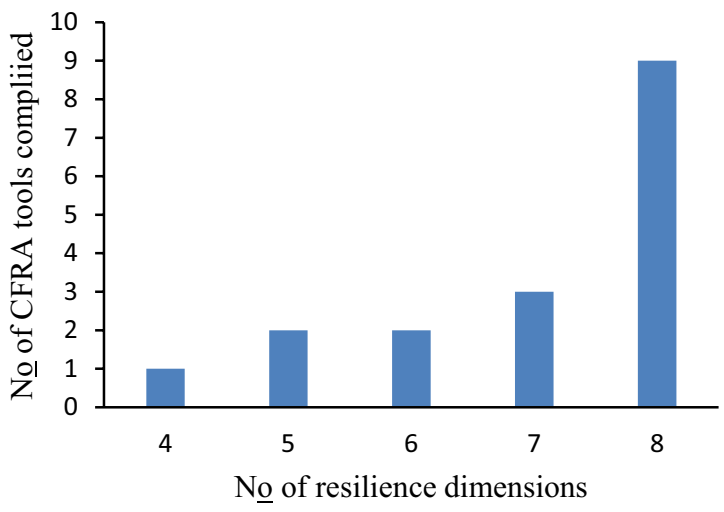

(b)

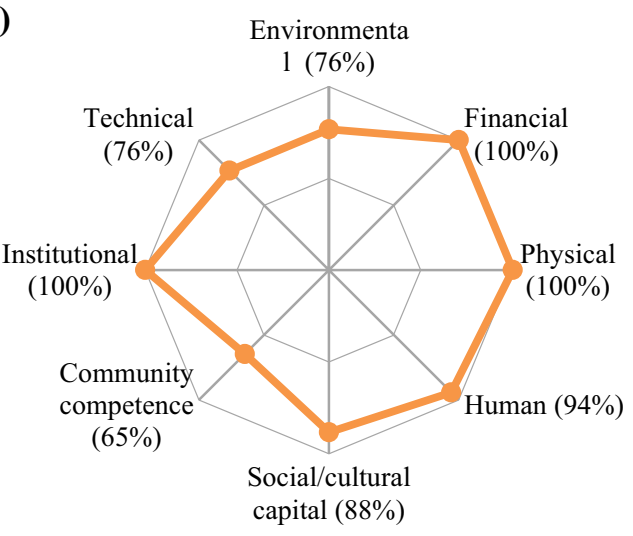

Fig. 1 Proportion of the analyzed community flood resilience assessment tools with respect to a multi-dimensionality, $\mathbf{b}$ comprehensiveness

selected tools) out of which, eight tools responded with score less than $50 \%$ (Table 4).

On the other hand, information summarized in Table 5 shows the state of comply by the selected frameworks to the analysis criteria (except inclusiveness). The results demonstrate that only three tools (smaller than $20 \%$ of the analyzed tools) have addressed spatial scales selected for this study. By contrast, about one-half of the analyzed frameworks have been developed to measure resilience of a single spatial scale. Essentially, less attention has been paid to measure community flood resilience at a lower level (i.e., household or individual). From this, it can be seen that more efforts are required to further improve understanding of spatial interdependency of community flood resilience.

Measurements of community flood resilience in a temporal band (past, present, future) are marked particularly in about a quarter of the analyzed tools: PEOPLES, CCRI, FRI and ResilSIM. It is also evident that some proportion of the tools partially addressed this criterion by complying with two of the three conditions. More importantly, attempts to measure future flood resilience are found to be lesser. 
Table 5 The state of comply by the analyzed CFRA tools to evaluation criteria (except multi-dimensionality)

\begin{tabular}{|c|c|c|c|c|c|c|c|c|c|c|c|}
\hline \multirow[t]{2}{*}{ Tools } & \multicolumn{3}{|c|}{ Spatial scale } & \multicolumn{3}{|c|}{ Temporal scale } & \multirow[t]{2}{*}{$\begin{array}{l}\text { Uncer- } \\
\text { tainties }\end{array}$} & \multicolumn{2}{|c|}{$\begin{array}{l}\text { Characterization } \\
\text { and evaluation }\end{array}$} & \multirow[t]{2}{*}{ Weighting } & \multirow[t]{2}{*}{ Level of application } \\
\hline & Lower & Focal & Higher & Past & Present & Future & & Oc-Se & Oc-Oe & & \\
\hline CCR & $x$ & $\sqrt{ }$ & $x$ & $x$ & $\sqrt{ }$ & $x$ & $x$ & $x$ & $\sqrt{ }$ & $\mathrm{x}$ & Diagnostic \\
\hline CARRI & $x$ & $\sqrt{ }$ & $\sqrt{ }$ & $x$ & $\sqrt{ }$ & $x$ & $x$ & $x$ & $\sqrt{ }$ & $x$ & Diagnostic \\
\hline CDRF & $x$ & $x$ & $\sqrt{ }$ & $\sqrt{ }$ & $x$ & $x$ & $x$ & $x$ & $\sqrt{ }$ & $\sqrt{ }$ & Diagnostic \\
\hline PEOPLES & $\sqrt{ }$ & $\sqrt{ }$ & $\sqrt{ }$ & $\sqrt{ }$ & $\sqrt{ }$ & $\sqrt{ }$ & $x$ & $\sqrt{ }$ & $\sqrt{ }$ & $\sqrt{ }$ & Diagnostic \\
\hline CCRI & $x$ & $\sqrt{ }$ & $x$ & $\sqrt{ }$ & $\sqrt{ }$ & $\sqrt{ }$ & $\sqrt{ }$ & $\sqrt{ }$ & $x$ & $x$ & Diagnostic \\
\hline BDRI & $x$ & $x$ & $\sqrt{ }$ & $x$ & $\sqrt{ }$ & - & $x$ & $x$ & $\sqrt{ }$ & $x$ & Diagnostic \\
\hline FRI & $\sqrt{ }$ & $\sqrt{ }$ & $\sqrt{ }$ & $\sqrt{ }$ & $\sqrt{ }$ & $\sqrt{ }$ & $x$ & $\sqrt{ }$ & $\sqrt{ }$ & $\sqrt{ }$ & Diagnostic \\
\hline CDRS & $\sqrt{ }$ & $\sqrt{ }$ & $x$ & $x$ & $\sqrt{ }$ & $\sqrt{ }$ & $x$ & $x$ & $\sqrt{ }$ & $x$ & Diagnostic \\
\hline RCS & $x$ & $\sqrt{ }$ & $x$ & $x$ & $\sqrt{ }$ & $x$ & $x$ & $x$ & $\sqrt{ }$ & $x$ & Diagnostic \\
\hline CRMF & $\sqrt{ }$ & $\sqrt{ }$ & $\sqrt{ }$ & $\mathrm{x}$ & $\sqrt{ }$ & $x$ & $\mathrm{x}$ & $x$ & $\sqrt{ }$ & $\sqrt{ }$ & Diagnostic \\
\hline CRF & $x$ & $\sqrt{ }$ & $\sqrt{ }$ & $\sqrt{ }$ & $\sqrt{ }$ & $x$ & $\mathrm{x}$ & $\sqrt{ }$ & $x$ & $\mathrm{x}$ & Diagnostic, evaluative, planning \\
\hline FCR & $x$ & $\sqrt{ }$ & $x$ & $x$ & $\sqrt{ }$ & $x$ & $x$ & $x$ & $\sqrt{ }$ & $x$ & Diagnostic, evaluative, planning \\
\hline ADRI & $\mathrm{x}$ & $x$ & $\sqrt{ }$ & $\sqrt{ }$ & $x$ & $x$ & $\mathrm{x}$ & $x$ & $\sqrt{ }$ & $x$ & Diagnostic \\
\hline ResilSIM & $x$ & $\sqrt{ }$ & $x$ & $\sqrt{ }$ & $\sqrt{ }$ & $\sqrt{ }$ & $x$ & $x$ & $\sqrt{ }$ & $x$ & Diagnostic \\
\hline CRMT & $x$ & $\sqrt{ }$ & $\sqrt{ }$ & $\sqrt{ }$ & $\sqrt{ }$ & $x$ & $x$ & $\sqrt{ }$ & $x$ & $\sqrt{ }$ & Diagnostic, evaluative, planning \\
\hline CDRI & $x$ & $x$ & $\sqrt{ }$ & $\sqrt{ }$ & $x$ & $x$ & $x$ & $x$ & $\sqrt{ }$ & $\sqrt{ }$ & Diagnostic \\
\hline MFRC & $x$ & $\sqrt{ }$ & $x$ & $x$ & $\sqrt{ }$ & $\sqrt{ }$ & $\sqrt{ }$ & $x$ & $\sqrt{ }$ & $x$ & Diagnostic \\
\hline
\end{tabular}

$\sqrt{ }$ : indicates the criteria is addressed; $x$ : not addressed or no enough information is provided; Oc-Se: objective characterization and subjective evaluation; Oc-Oe: objective characterization and objective evaluation

By contrast, more than one-half of the analyzed frameworks have been developed mainly to measure resilience of single time condition either present or past condition. However, assessment of only single time cannot reflect evolving characteristics of resilience.

The table also illustrates the extent to which attempts have been made in addressing the issue of uncertainties in flood resilience measurement. With this respect, only two tools (CCRI and MRFC) have made effort to address uncertainties through scenario making and planning for the most extreme events. While it is a critical issue in flood risk management, it has received little attention in the significant proportion of the analyzed tools (about 88\%).

Analysis in regard to the characterization and implementation of resilience indicators in each of the selected frameworks indicates that all the analyzed frameworks are developed through literature review and expert input. This reveals that attention paid to adopt a participatory approach, particularly, involvement of community, in the development of the selected tools appears insignificant, yet few frameworks have been implemented through community participation.

Further, the results indicate that in the majority of the frameworks, all indicators are considered equally important toward explaining the level of community resilience to flood. However, it can also be seen from Table 5 that weighting approach has been used by nearly one-third of the developers to address the relative contribution of indicators. In these frameworks, weight is assigned based on experts' view, through analytical hierarchical process (AHP). However, such approach is unlikely free from a certain level of subjectivity.

Finally, by assessing the functions to which the frameworks have been designed, it is identified that the selected frameworks can be used for one or more purposes (diagnostic, planning and evaluation). Application of a community flood resilience tool in all the identified functions have been demonstrated in three tools: CRF, FCR, CRMT. However, in the rest of the selected frameworks diagnostic purpose is found to be a common function for which the tools are developed.

\section{Discussion}

In response to inadequacy of the flood control infrastructures under uncertainties, building community resilience has become a concern of modern flood risk management. Relatedly, there has been growing recognition of the importance of community flood resilience measurement. The idea of resilience measurement is relatively a new and developing area of research and practice $[24,29]$. In the past few decades, several tools to measure resilience have been introduced based on a unique understanding of the 
concept of resilience in the sectors they proposed from. Among others, resilience measurement helps to identify existing gaps, to choose options for building resilience, to monitor progress and to evaluate the success of interventions (e.g., policies, projects, programs) against their intended objectives [25-32]. However, overall yield from resilience building actions can be compromised if the measurements do not conform to theoretical basis.

This study was conducted mainly to provide an insight into the extent to which the multifaceted nature of resilience has been addressed in the existing CFRA tools and to pinpoint improvements needed to enhance their effectiveness and operationalization of the concept. With this respect, seventeen CFRA frameworks were selected. By taking multifaceted nature of resilience into account, seven evaluation criteria were defined through which the selected CFRA tools are analyzed.

Findings show that some of the evaluation criteria have not been fittingly addressed by the analyzed CFRA tools. First, a large proportion of indicator related to community competence dimension has been unnoticed by a significant proportion of the analyzed tools. It has been argued that from a disaster risk management perspective, comprehensive set of indicators can help to capture greater detail effectively [32]. In addition, comprehensive resilience measurement allows to direct efforts not only toward improving the weakness, but also toward promotion of existing strength. Moreover, in a complex system, decisions about what establishes resilience are challenging $[2,36]$. In addition to weighting individual indicators within respective flood resilience dimensions, comprehensive measurement using all dimensions can be used as a means to reduce an unavoidable subjectivity related to the decisions about which dimensions must be included.

It is also found that the issue of uncertainties is not addressed well by selected tools. Uncertainties are critical feature in community resilience under likely most extreme floods emerging from climate change and urbanization. Hence, assessing community flood resilience under such conditions is necessary for effective planning of resilience building actions. Flood modeling techniques through combinations of different flood return periods and lower and upper bound climate change scenarios can be used to generate flood inundation maps, which in turn can help to assess resilience at most extreme conditions.

The limited participation of community in the development of the analyzed tools is another important finding of this study. Assessing social aspects of resilience cannot be fully acquired through only objective approach, which is usually related to externally defined resilience characteristics [40] since resilience is not the same for all. In this regard, perceptions, judgments and preferences of communities being assessed have significant importance for improving reliability and acceptability assessment results; at the same time, it supports the implementation of action plans. Collaborative approach can also allow to ensure the contextual significance of the overall aim and the specific intervention strategies. Hence, efforts to promote these benefits should boost community involvement in flood resilience assessment.

In some of the analyzed frameworks, weighting techniques is used to consider the relative importance of indicators. Weighting the resilience indicators is important to emphasis indicators with greater contribution to resilience that can improve effectiveness of planning for resilience building. However, it should be noted that weight has a potential to influence sensitivity of an index that obtained by aggregating scores of weighted indicators [71], and its assignment requires a well-established method. Hence, in order to maintain benefits and establish consistency between assessment approaches, development of theoretically anchored, practically valid and applicable weighting approach demands further attention.

In general, the study reveals that the selected CFRA tools reflect certain limitations to address some of the analysis criteria. Meaning, application of the frameworks in isolated manner can only provide a portion of multifaceted nature of resilience; at the same time, it highlights inconsistency of community flood resilience measurements. The result of this study is pertaining to the analyzed tools against identified evaluation criteria and could be used as a baseline study for flood resilience measurement tools in general. Still, it cannot be interpreted as the frameworks are inadequate to measure resilience of a community, since they are designed and verified depending on their own purposes. In addition, it should be noted that the study has made no attempt to score or rank the frameworks.

With respect to the growing concern of establishing consistency in community flood resilience measurement and improved understanding and operationalization of the resilience concept in flood risk management in particular, and in resilience field in general, this study provides significant contributions. First, the findings can be used in updating or revising the analyzed frameworks toward addressing multifaceted nature of resilience. In addition, the identified analysis criteria highlight main features need to be addressed in the community flood resilience measurement that can support future attempts to develop and implement new CFRA tools. Consequently, it can support the efforts being made to establish a consistent basis for robust community flood resilience measurement.

Second, the synthesized information (i.e., tabular summaries) related to the main features of the analyzed CFRA frameworks in this study can help actors (e.g., planners, researchers, development partners, authorities at both 
local and national levels) in the selection and integration of assessment tools under different settings. The purposes of resilience measurement frameworks can be ductile. For example, those frameworks primarily designed for diagnostic purpose could be used for evaluative purposes, as they can be applied initially for baseline assessment. Hence, most of the frameworks analyzed in this study can be applied for assessing progress in resilience in the setting of resilience building programs/projects. However, attention has to be paid to constraints that could arise from the primary focus of the frameworks, since any given framework is usually better suited to a particular purpose. On the other hand, it should be noted that comprehensive measurement is not necessarily better or more useful, as it could result in increased complexity and demands more resources. Hence, in order to make appropriate choice between the frameworks or to integrate features of different frameworks, it is essential to think about the contexts to which the resilience being assessed and built.

Third, the diverse understanding and application of the resilience concept in various disciplines has been noted as a positive indicator of improved insight and operationalization of the concept of resilience [28]. With this regard, this study provides a scientific evidence on how resilience measurement is being operationalized in the context of community flood resilience, thereby contributing to understanding how resilience is being learnt from different disciplines.

Finally, on top of satisfying the objective of the study, evaluation methodology defined and applied here could have broader applications. For instance, the multi-dimension of community flood resilience defined in this study highlights the capacities that are needed for resilience building, thus can serve as a base for practical activities aim at improving community resilience to flood. Moreover, an approach used in this study is easily replicable, and it could be used in further studies with or without the addition of criteria specific to a different field of study.

\section{Conclusions}

By identifying evaluation methodology which takes the multifaceted nature of resilience into account, this study analyzed existing community flood resilience measurement tools. The results reveal that multifaceted nature of resilience appears inadequately addressed in existing CFRA frameworks and measurements of community flood resilience tends to be inconsistent.

With respect to the increasing concern of establishing consistent and robust ways of community flood resilience measurement as well as improved understanding and operationalization of the resilience concept in flood risk management, considerable improvements are needed. In essence, efforts to assess community competence can increase multi-dimensionalities of the frameworks. Improved understanding of the importance of detailed information to obtain a broad picture of resilience could promote the application of comprehensive indicators set in resilience assessment process. Improvements could also come from adopting participatory approach and acknowledging the importance of flood resilience measurement under uncertainties. Moreover, it is necessary to understand the limits that arise from resilience measurement at only a single spatial scale and taking snapshot measurements in time.

Ideally, in order to provide a full picture of community flood resilience and capitalize the benefits from resilience concept, it is essential to consider all of the criteria in development and implementation of assessment framework. However, this may not be always possible due to certain limitations (e.g., financial, institutional). Hence, attempts to build community resilience at certain stages in flood risk management cycle may require prioritizing the criteria based on their relative contribution to the required purpose.

The findings of this study can be used in updating or revising the analyzed tools and provide a guidance for development and implementation of new tools. In addition, it supports stakeholders aim to build community flood resilience to choose, arrange and integrate the frameworks under different settings. Above all, it provides insight how the concept of resilience measurement is being operationalized in the context of community flood resilience. The criteria applied in the analysis of CFRA frameworks in this study were extracted from the literature. Nevertheless, feedback from practical application of the frameworks can offer complementary insight on the operationalization of the concept of resilience in flood risk management. It is also recommended that studies are required to develop theoretically as well as a practically justified weighting approach that can allow consistent delineation of relative importance of the resilience indicators.

Acknowledgements This paper is a part of ongoing $\mathrm{PhD}$ dissertation by Dejene Tesema Bulti at Ethiopian Institute of Architecture, Building Construction and City Development (EiABC), Addis Ababa University, Ethiopia. We would like to thank the anonymous reviewers and the editor for their genuine comments and corrections which helps the paper to be in its present form.

Authors' contributions DTB conceived the study and made contributions in design, analysis, interpretation of results and drafting the manuscript. BG and TL contributed to critical comments on the manuscript. All authors read and approved the manuscript.

Availability of data and material Not applicable. 


\section{Compliance with ethical standards}

Conflict of interest The authors affirm that there is no conflict of interest at all in this research.

Consent for publication We have agreed to submit for SN Applied Sciences journal and approved the manuscript for submission.

Ethics approval and consent to participate Not applicable.

\section{References}

1. Tingsanchal T (2012) Urban flood disaster management. Procedia Eng 32(2012):25-37

2. Keating A, Campbell K, Mechler R, Michel-Kerjan E, Mochizuki $J$ et al (2014) Operationalizing resilience against natural disaster risk: opportunities, barriers and a way forward. Zurich Flood Resilience Alliance, Zurich

3. Parsasyrat $L$, Jamali A (2015) The effects of impermeable surfaces on the flooding possibility in ZarrinShahr, Isfahan Municipal Watershed. J Appl Environ Biol Sci 5(1):28-38

4. Batica J, Gourbesville P (2016) Resilience in flood risk management-a new communication tool. In: 12th International conference on hydroinformatics, HIC 2016. Procedia Engineering, vol 154, pp 811-817

5. Abshirini E, Koch D, Legeby A (2017) Flood resilient cities: a syntactic and metric novel on measuring the resilience of cities against flooding. J Geogr Inf Syst 9:505-534

6. Liao K (2012) A theory on urban resilience to floods-a basis for alternative planning practices. Ecol Soc 17(4):48. https://doi. org/10.5751/ES-05231-170448

7. Yeo S (2013). A review of flood resilience in Fiji. In: International conference on flood resilience: experiences in Asia and Europe 5-7 September 2013, Exeter, UK

8. Rosenzweig BR, McPhillips L, Chang H, Cheng C, Welty C, Matsler M, Iwaniec D, Davidson Cl (2018) Pluvial flood risk and opportunities for resilience. WIREs Water. https://doi.org/10.1002/ wat2.1302

9. Barroca B, Pacteau C (2018) Resilience and urban design: what does the French flood of 2016 teach us? TECHNE 15(2018):3138. https://doi.org/10.13128/Techne-23199

10. Zevenbergen C, Gersonius B (2007) Challenges in urban flood management. In: Advances in urban flood management. CRC Press, pp 1-11

11. Hughes J, Sharman B (2015) Flood resilient communities: a framework and case studies. In: Asia Pacific stormwater conference

12. Hegger DLT, Driessen PPJ, Wiering $M$, Van Rijswick HFMW, Kundzewicz ZW, Matczak P, Crabbé A, Raadgever GT, Bakker MHN, Priest SJ, Larrue C, Ek K (2016) Toward more flood resilience: is a diversification of flood risk management strategies the way forward? Ecol Soc 21(4):52. https://doi.org/10.5751/ ES-08854-210452

13. Atreya A, Kunreuther $\mathrm{H}$ (2016) Measuring community resilience: the role of the community rating system (CRS). Working paper \# 2016-07

14. Batica J, Gourbesville P, Hu F (2013) Methodology for flood resilience index. In: International conference on flood resilience: experiences in Asia and Europe

15. Quinlan AE, Blazquez MB, Haider LJ, Peterson GD (2016) Measuring and assessing resilience. J Appl Ecol 53:677-687

16. Meerow $S$, Joshua P, Newell JP, Stults M (2016) Defining urban resilience: a review. Landsc Urban Plan 147:38-49
17. Walker B, Holling CS, Carpenter SR, Kinzig A (2004) Resilience, adaptability and transformability in social-ecological systems. Ecol Soc 9(2):5. https://doi.org/10.5751/es-00650-090205

18. Berkes $F$ (2007) Understanding uncertainty and reducing vulnerability: lessons from resilience thinking. Nat Hazards 41:283-295

19. Bruijn KM (2004) Resilience indicators for flood risk management systems of lowland rivers. Int J River Basin Manag 2(3):199-210

20. Ashley RM, Blanksby J, Cashman A, Newman R (2007) An adaptable approach to flood risk management for local urban drainage. Defra Flood and Coastal Erosion Conference, York

21. Balsells M, Barroca B, Becue V, Serre D (2015) Making urban flood resilience more operational: current practice. Water Manag. https://doi.org/10.1680/wama.14.00051

22. Schanze J (2016) Resilience in flood risk management_Exploring its added value for science and practice. In: Flood risk 2016 - 3rd European conference on flood risk management. https://doi. org/10.1051/e3sconf/20160708003

23. Oladokun V, Proverbs D, Lamond J (2017) Measuring flood resilience: a fuzzy logic approach. Int J Build Pathol Adapt 35(5):470 487. https://doi.org/10.1108/IJBPA-12-2016-0029

24. Shin S, Lee $S$, Judi DR, Parvania M, Goharian E, McPherson T, Burian SJ (2018) A systematic review of quantitative resilience measures for water infrastructure systems. Water 10:164. https ://doi.org/10.3390/w10020164

25. Bene C (2013) Towards a quantifiable measure of resilience. Institute of Development Studies working paper 434

26. TRF (2015) City resilience index: city resilience framework. The Rockefeller Foundation and ARUP

27. Taylor A, Jackson B, Jones E, Nashed S, Reichow A, Smith A (2015) Measuring for results application of key concepts to resilience measurement. Homeland security studies and analysis institute

28. Keating A, Campbell K, Szoenyi M, McQuistan C, Nash D, Burer M (2017) Development and testing of a community flood resilience measurement tool. Nat Hazards Earth Syst Sci 17:77-101

29. Schipper ELF, Langston $L$ (2015) A comparative overview of resilience measurement frameworks: analyzing indicators and approaches. Working paper 422

30. ODI (2016) Resilience measurement frameworks and approaches: a Bird's Eye view. resilience, measurement, evidence and learning community of practice (CoP). Overseas Development Institute, London

31. Constas M, Cisse J, Knippenberg E, Downie K (2016) A focused review of methodologies to measure resilience: an analysis of conceptual presentations, indicators, and estimation procedures. Report prepared by The Technical Consortium, a project of the CGIAR. Technical Report Series No 2: Strengthening the Evidence Base for Resilience in the Horn of Africa. Nairobi, Kenya: A joint International Livestock Research Institute (ILRI) and Charles H. Dyson School of Applied Economics and Management, College of Agriculture and Life Sciences, Cornell University publication

32. Winderl T (2014) Disaster resilience measurements: stocktaking of ongoing efforts in developing systems for measuring resilience. United Nations Development Program, New York

33. Lavelle FM, Ritchie LA, Kwasinski A, Wolshon B (2015) Critical assessment of existing methodologies for measuring or representing community resilience of social and physical systems. National Institute of Standards and Technology, Gaithersburg

34. Norris FH, Stevens SP, Pfefferbaum B, Wyche KF, Pfefferbaum $\mathrm{RL}$ (2008) Community resilience as a metaphor, theory, set of capacities, and strategy for disaster readiness. Am J Community Psychol 41:127-150. https://doi.org/10.1007/s1046 4-007-9156-6

35. Bahadur A (2016) Analysis of resilience measurement frameworks and approaches. Working paper. https://doi.org/10.13140 /rg.2.2.13892.94082 
36. Cumming GS, Barnes G, Perz S, Schmink M, Sieving KE, Southworth J et al (2005) An exploratory framework for the empirical measurement of resilience. Ecosystems 8:975-987. https ://doi.org/10.1007/s10021-005-0129-z

37. Cutter SL, Barnes L, Berry M, Burton CG, Evans E, Tate EC, Webb $J$ (2008) Community and regional resilience: perspectives from hazards, disasters, and emergency management. In: CARRI Research Report 1, Community and Regional Resilience Institute, Oak Ridge, TN

38. Frankenberger T, Mueller M, Spangler T, Alexander S (2013) Community resilience: conceptual framework and measurement feed the future learning agenda. Westat, Rockville

39. Monaghan P, Ott E, Fogarty T (2014) Measuring community resilience using online toolkits. AEC507, UF/IFAS Extension Service, University of Florida

40. Jones $L$ (2018) Resilience isn't the same for all: comparing subjective and objective approaches to resilience measurement. WIREs Clim Change. https://doi.org/10.1002/wcc.552

41. Gonzva M, Barroca B (2017) Improving urban infrastructures resilience using conceptual models: application of the "Behind the Barriers" model to the flooding of a rail transport system. In: 7th Resilience engineering association symposium, Jun 2017, Liège, Belgium. hal-01677368

42. Cutter SL, Burton CG, Emrich CT (2010) Disaster resilience indicators for benchmarking baseline conditions. J Homel Secur Emerg Manag 7(1):51. https://doi. org/10.2202/1547-7355.1732

43. Parsons M, Morley P, Marshall G, Hastings P, Glavac S, Stayner $R$ et al (2016) The Australian Natural Disaster Resilience Index: conceptual framework and indicator approach. Bushfire and Natural Hazards CRC, Melbourne

44. VNRC (2013) The resilient communities scorecard: a tool for assessing your community. Vermont Natural Resources Council, New York

45. Arbon P, Gebbie K, Cusack L, Perera S, Verdonk S (2014) Developing a model and tool to measure community disaster resilience. Austral J Emerg Manag 29(4):12-16

46. Irwin S, Schardong A, Simonovic S, Nirupama N (2016) ResilSIM-a decision support tool for estimating resilience of urban systems. Water 8:377. https://doi.org/10.3390/w8090 377

47. USIOTWSP, U.S. Indian Ocean Tsunami Warning System Program (2007) How resilient is your coastal community? A guide for evaluating coastal community resilience to Tsunamis and other coastal hazards. U.S. Indian Ocean Tsunami Warning System Program, Bangkok

48. Mayunga JS (2009) Measuring the measure: a multi-dimensional scale model to measure community disaster resilience in the U.S. Gulf Coast Region. Dissertation. Texas A\&M University

49. Renschler CS, Frazier AE, Arendt LA, Cimellaro GP, Reinhorn AM, Bruneau M (2010) Developing The 'PEOPLES' resilience framework for defining and measuring disaster resilience at the community scale. In: Proceedings of the 9th U.S. National and 10th Canadian Conference on Earthquake Engineering. July 25-29, 2010, Toronto, Ontario, Canada

50. Renschler CS, Frazier AE, Arendt LA, Cimellaro GP, Reinhorn AM, Bruneau M (2010) A framework for defining and measuring resilience at the community scale: the PEOPLES resilience framework. Technical Report MCEER-10-0006. National Institute of Standards and Technology (NIST)

51. NIST (2016) Community resilience planning guide for buildings and infrastructure systems, Volume II. National Institute of Standards and Technology Special Publication 1190-1. https ://doi.org/10.6028/nist.sp.1190v2
52. Sempier TT, Swann DL, Emmer R, Sempier SH, Schneider M (2010) Coastal community index: a community self-assessment. MASGP-08-014

53. Batica J (2015) Methodology for flood resilience assessment in urban environments and mitigation strategy development. Other. Université Nice Sophia Antipolis, Nice

54. Arbon P, Steenkamp M, Cornell V, Cusack L, Gebbie K, Amaratunga $D$ (2016) Measuring disaster resilience in communities and households: pragmatic tools developed in Australia. Int J Disaster Resil Built Environ 7:201-215. https://doi. org/10.1108/IJDRBE-03-2015-0008

55. IFRC (2014) IFRC framework for community resilience. International Federation of Red Cross and Red Crescent Societies, Geneva

56. Feofilovs M, Romagnoli F (2017) Measuring community disaster resilience in the Lativian context: an apply case using a composite indicator approach. International scientific conference "environmental and climate technologies", CONECT 2016. Energy Procedia 113:43-50

57. MCP (2017) Maine flood resilience checklist. A self-assessment tool for Maine's coastal communities to evaluate vulnerability to flood hazards and increase resilience. Maine Coastal Program

58. NIST (2015) Community Resilience planning guide for buildings and infrastructure systems, Volume I. National Institute of Standards and Technology Special Publication 1190. https ://doi.org/10.6028/nist.sp.1190v1

59. IMPROVER (2016) Improved Risk Evaluation and Implementation of Resilience Concepts to Critical Infrastructure. International Survey

60. Twigg J (2009) Characteristics of a disaster-resilient community: a guidance note (version 2). https://discovery.ucl.ac.uk/ id/eprint/1346086/1/1346086.pdf

61. Nelson D, Adger W, Brown K (2007) Adaptation to environmental change: contributions of a resilience framework. Annu Rev Environ Resour 32:395-419

62. Bruneau M, Chang SE, Eguchi RT, Lee GC, O'Rourke TD, Reinhorn AM et al (2003) A framework to quantitatively assess and enhance the seismic resilience of communities. Earthq Spectra 19(4):733-752

63. Sharifi A, Yamagata Y (2016) Urban resilience assessment: multiple dimensions, criteria, and indicators. In: Urban resilience, advanced sciences and technologies for security applications, pp 259-276. https://doi.org/10.1007/978-3-319-39812-9_13

64. Aldrich DP (2012) Social capital in post disaster recovery: towards a resilient and compassionate East Asian Community. In: Sawada Y, Oum S (eds) Economic and welfare impacts of disasters in East Asia and policy responses. ERIA Research Project Report 2011-8 Jakarta: ERIA, pp 157-178

65. DFID (1999) Sustainable livelihoods guide sheets. Department for International Development, London

66. Chandra A, Acosta J, Stern S, Uscher-Pines L, Williams MV (2011) Building community resilience to disasters: a way forward to enhance national health security. Rand Corporation, Santa Monica

67. Choularton R, Frankenberger T, Kurtz J, Nelson S (2015) Measuring shocks and stressors as part of resilience measurement. Resilience measurement technical working group. Technical series no. 5. Food Security Information Network, Rome

68. Ward PJ, de Moel H, Aerts JCJH (2011) How are flood risk estimates affected by the choice of return-periods? Nat Hazards Earth Syst Sci 11:3181-3195. https://doi.org/10.5194/nhess $-11-3181-2011$

69. Serre D, Barroca B, Balsells M, Becue V (2016) Contributing to urban resilience to floods with neighborhood design: the 
case of Am Sandtorkai/Dalmannkai in Hamburg. J Flood Risk Manag 11:S69-S83. https://doi.org/10.1111/jfr3.12253

70. Jones L, Samman E (2016) Measuring subjective household resilience: insights from Tanzania. Working paper. BRACED

71. Tate E (2012) Social vulnerability indices: a comparative assessment using uncertainty and sensitivity analysis. Nat Hazards. https://doi.org/10.1007/s11069-012-0152-2
Publisher's Note Springer Nature remains neutral with regard to jurisdictional claims in published maps and institutional affiliations. 